\title{
The Onset of Urinary Incontinence in Different Subgroups and its Relation to Menopausal Status: A Hospital-based Study
}

\author{
FABINSHY THANGARAJAH ${ }^{1 *}$, JESSICA HARTMANN-WOBBE $^{1 *}$, DOMINIK RATIU ${ }^{1}$, CAROLINE PAHMEYER $^{1}$, \\ JULIA CAROLINE RADOSA ${ }^{2}$, PETER MALLMANN ${ }^{1}$ and SEBASTIAN LUDWIG ${ }^{1}$ \\ ${ }^{1}$ Department of Obstetrics and Gynecology, University Hospital Cologne and Medical Faculty, Cologne, Germany; \\ ${ }^{2}$ Clinic for Gynecology, Obstetrics and Reproductive Medicine, \\ Saarland University Medical Center, Homburg, Germany
}

\begin{abstract}
Background/Aim: Numerous risk factors have been reported to influence the development of urinary incontinence (UI). In this study, we took a closer look on the different forms of UI and tried to identify differences in regard to potential risk factors. Of special interest was the onset of UI symptoms and its relation to menopausal status. Patients and Methods: This was a hospital-based analysis of patients who presented with urinary incontinence in the outpatient ward of a tertiary hospital. The diagnosis of urinary incontinence was based on the subjective complaints of patients. Data concerning menopausal status, hormone replacement therapy, prior hysterectomy were assessed. Results: The mean age was 53.8 years in the SUI group, 62.7 years in the MUI group and 66.1 years in the UUI group, respectively $(p<0.001)$. The proportion of patients with UUI was higher in the postmenopausal group, whereas the proportion of SUI was higher in the premenopausal group $(p<0.001)$. The mean age in which complaints occurred was significantly lower in the SUI group (45.4 years) compared to the MUI (51.0 years) and UUI groups (54.7 years) $(p<0.001)$. There was no correlation between menopausal status and onset of urinary incontinence ( $p=0.143)$. Conclusion: Additional anamnestic information help further characterize the different types of urinary incontinence that can lead to an optimization of treatment options. Younger age and premenopausal status were accompanied by milder forms of UI while menopausal status itself had no influence on the onset of
\end{abstract}

This article is freely accessible online.

*These Authors contributed equally to this study.

Correspondence to: Sebastian Ludwig, Department of Obstetrics and Gynecology, Medical Faculty, University Hospital Cologne, Kerpener Str. 34, 50931 Cologne, Germany. Tel: +49 22147897303, email: Sebastian.Ludwig@uk-koeln.de

Key Words: Mixed urinary incontinence, urgency urinary incontinence, stress urinary incontinence, menopause, hormonal therapy.
UI symptoms indicating that age-related changes may lead to different types of incontinence.

Urinary incontinence (UI) is a common problem among women. Up to $75 \%$ of women of varying age groups experience UI, especially up to $33 \%$ of women suffering from bothersome urgency urinary incontinence (UUI) (1). Some risk factors have been reported to influence development of UI. It has been associated with prior hysterectomy, but studies show varying results regarding the association between the type of hysterectomy and UI (2-5). Further important risk factors are age, obstetric trauma and obesity. These risk factors may also affect the development of UI $(2,6,7)$. Vaginal delivery, menopausal status, as well as hormone replacement therapy are also known to influence lower urinary tract symptoms $(8,9)$.

Even though several factors have been reported to be associated with UI, published data about these factors are inconsistent and comprehensive data about risk factors in different subtypes of urinary incontinence are still lacking. Hence, we aimed to identify risk factors for the development of the different types of incontinence in a hospital-based analysis. Of special interest was the onset of UI and its relation to menopausal status.

\section{Patients and Methods}

This was a hospital-based retrospective analysis of patients who presented with urinary incontinence in the outpatient ward of the University Hospital of Cologne between 2013 and 2018. The diagnosis of urinary incontinence was based on the subjective complaints of patients, rather than on urodynamic studies. The complaints of patients were registered by using a modification of the long version of the ICIQ questionnaire (10). The main difference was that we omitted the categorization of extent of bothering after each question. The questionnaire was explained in an interview by the authors and a study nurse. Stress urinary incontinence (SUI) was defined as the involuntary loss of urine when increasing the intraabdominal pressure by coughing, sneezing, or exercise. Urgency urinary incontinence (UUI) was defined as involuntary loss of urine without any control nearly immediately after the first feeling of 
Table I. Patient characteristics.

\begin{tabular}{|c|c|c|c|c|c|}
\hline & Overall cohort & SUI & MUI & UUI & $p$-Value \\
\hline Age (years) & $62.1(12.8)$ & $53.8(13.2)$ & $62.7(12.4)$ & $66.1(10.9)$ & $<0.001$ \\
\hline Spontaneous delivery (\%) & & & & & 0.648 \\
\hline 0 & 10.8 & 6.3 & 11.8 & 10.2 & \\
\hline $1-2$ & 62.2 & 63.7 & 61.5 & 64.3 & \\
\hline$\geq 3$ & 26.9 & 30.0 & 26.7 & 25.5 & \\
\hline Menopausal status $(\%)$ & & & & & $<0.001$ \\
\hline Premenopausal & 18.4 & 46.3 & 15.3 & 8.9 & \\
\hline Postmenopausal & 81.6 & 53.7 & 70.5 & 91.1 & \\
\hline Prior hysterectomy (\%) & & & & & 0.003 \\
\hline Yes & 50.2 & 32.9 & 53.7 & 49.5 & \\
\hline No & 49.8 & 67.1 & 46.3 & 50.5 & \\
\hline \multicolumn{6}{|l|}{$\begin{array}{l}\text { Subgroup analysis of } \\
\text { postmenopausal patients }\end{array}$} \\
\hline Age at menopause onset & $49.0(5.08)$ & $49.2(4.5)$ & $48.8(5.1)$ & $49.5(5.07)$ & 0.457 \\
\hline Hormone replacement therapy (\%) & & & & & 0.950 \\
\hline Yes & 38.5 & 36.4 & 38.6 & 39.1 & \\
\hline No & 61.5 & 63.6 & 61.4 & 60.9 & \\
\hline
\end{tabular}

urgency. Mixed urinary incontinence (MUI) was defined as symptoms of both SUI and UUI. Data regarding menopausal status, hormone therapy, prior incontinence surgery, and prior hysterectomy were assessed according to the patients' data sheets.

Statistical analysis. Patient characteristics are described using absolute numbers (percentage) or mean \pm standard deviation (SD), as appropriate. Associations between two qualitative variables were tested using $\mathrm{Chi}^{2}$-test or Fisher's exact test, as appropriate. A one-sided analysis of variance was performed for metric variables. If the F-test was significant, a post-hoc-test was performed. In homogenic variances the alpha-error was adjusted with Bonferroni correction. All reported $p$-values are two sided and values of $p<0.05$ were considered statistically significant. Statistical analyses were performed using SPSS 25 (IBM Corp., Armonk, NY, USA).

\section{Results}

In total, 620 patients with UI were included in this retrospective analysis. Overall, $13.2 \%$ of patients presented with SUI, 70.5\% MUI and $16.3 \%$ presented with UUI, respectively. An overview of patient characteristics is presented in Table I.

Patient age and distribution of UI types. The mean age of the patients in was 62.1 years in the overall cohort. Within the subgroups the mean age was 53.8 years in the SUI group, 62.7 years in the MUI group and 66.1 years in the UUI group, respectively. The difference between the groups was statistically significant $(p<0.001)$.

Spontaneous delivery. About $10.8 \%$ of the patients were nulliparous, whereas $62.2 \%$ had 1 or 2 spontaneous deliveries and $26.9 \%$ had 3 or more spontaneous deliveries. There was no significant correlation to the type of incontinence $(p=0.648)$.

Menopausal status. Among all patients, $18.4 \%$ were pre- and $81.6 \%$ were postmenopausal. When we compared pre- and postmenopausal patients the distribution of the three types of incontinence was significantly different. The proportion of patients with UUI was higher in the postmenopausal group, whereas the proportion of SUI was higher in the premenopausal group $(p<0.001)$.

Prior hysterectomy. Overall, 50.2\% of patients had a prior hysterectomy in their medical history. The correlation between prior hysterectomy and the type of incontinence was statistically significant $(p=0.003)$.

Hormone replacement therapy. In a subgroup analysis of postmenopausal patients $38.5 \%$ received hormone replacement therapy. There was no significant correlation between hormone replacement therapy and incontinence groups $(p=0.950)$.

Patient age at onset of symptoms. We asked patients when the first symptoms of incontinence began. The mean age in which complaints began was significantly lower in the SUI group (45.4 years) compared to the MUI (51.0 years) and UUI group (54.7 years) $(p<0.001)$ (Figures 1-3).

Onset of menopause. The mean age at the beginning of menopause was $49.0( \pm 5.08)$ years in the overall cohort. The difference between the groups was not significant $(p=0.457)$. 


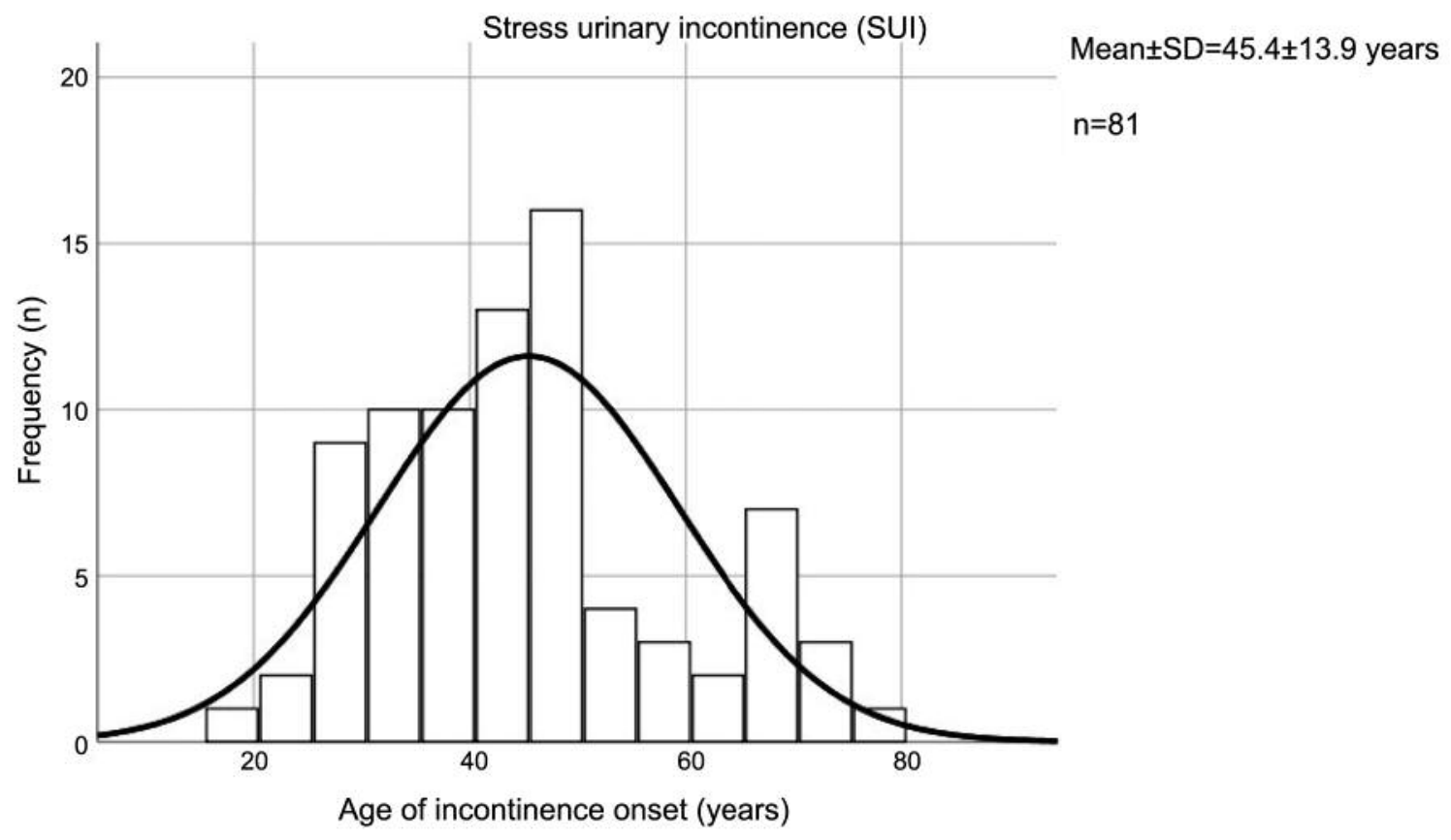

Figure 1. Onset of symptoms in patients presenting with stress urinary incontinence.

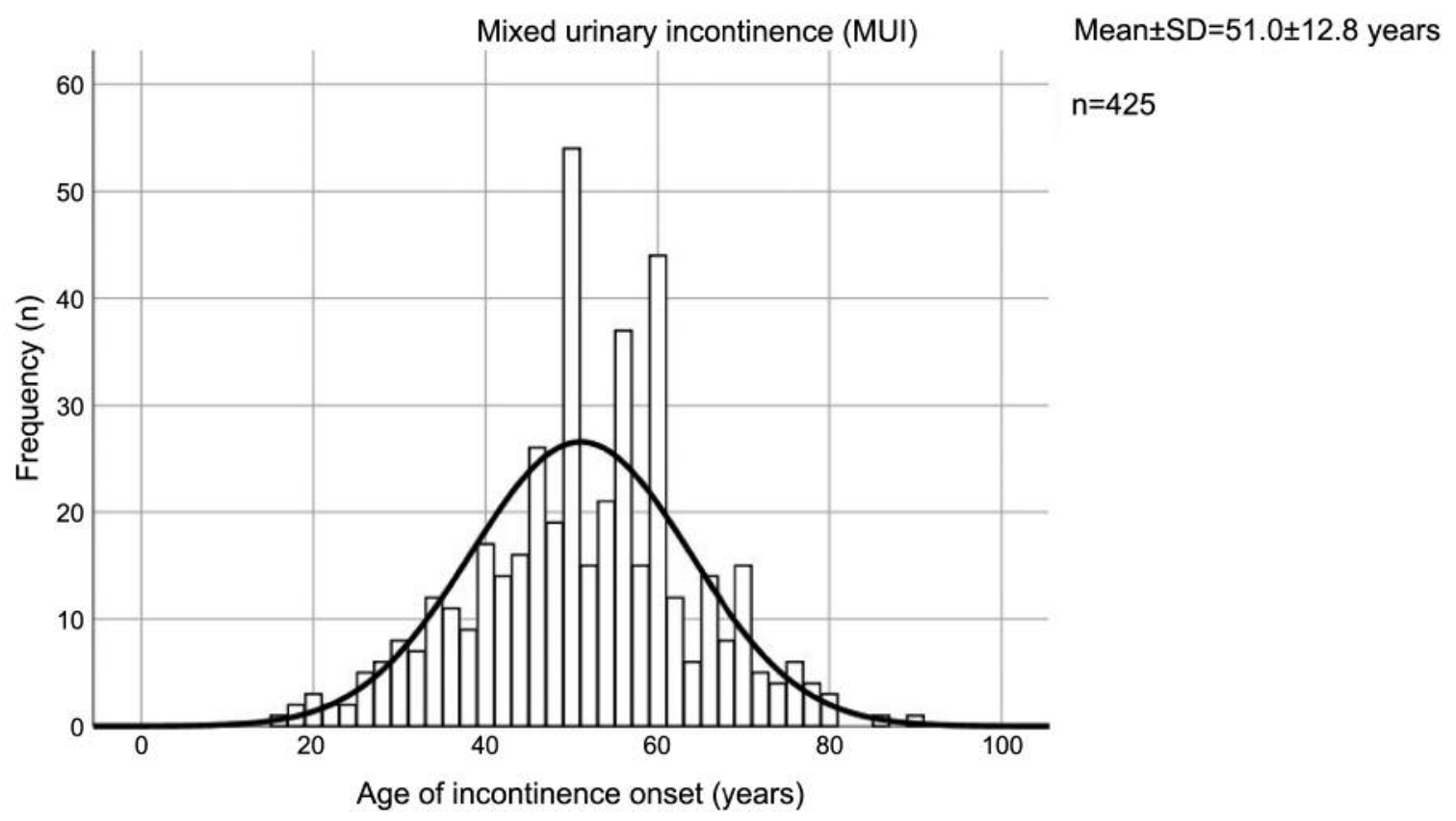

Figure 2. Onset of symptoms in patients presenting with mixed urinary incontinence.

Onset of symptoms in relation to menopausal status. Furthermore, we analyzed the correlation between the beginning of the menopause and the onset of the urinary incontinence. There was no significant correlation between the onset of incontinence and the menopausal status $(p=0.143)$ (Figure 4).

\section{Discussion}

This study showed that age at presentation and at onset of UI symptoms was significantly different in the different study groups, whereas the onset of menopause and spontaneous deliveries did not have any influence on the UI type. 


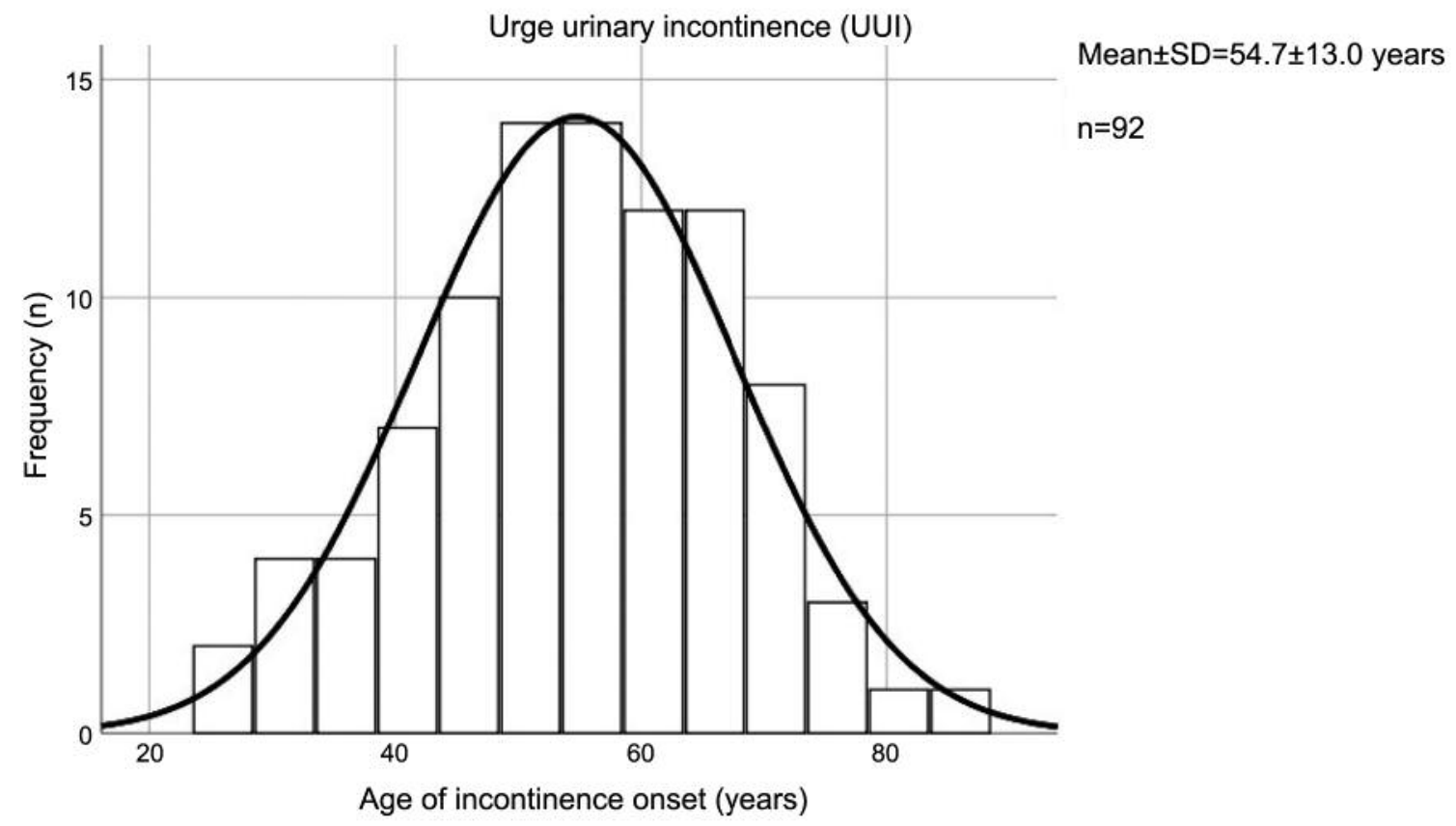

Figure 3. Onset of symptoms in patients presenting with urge urinary incontinence.

\section{Begin of symptoms in relation to menopausal status}

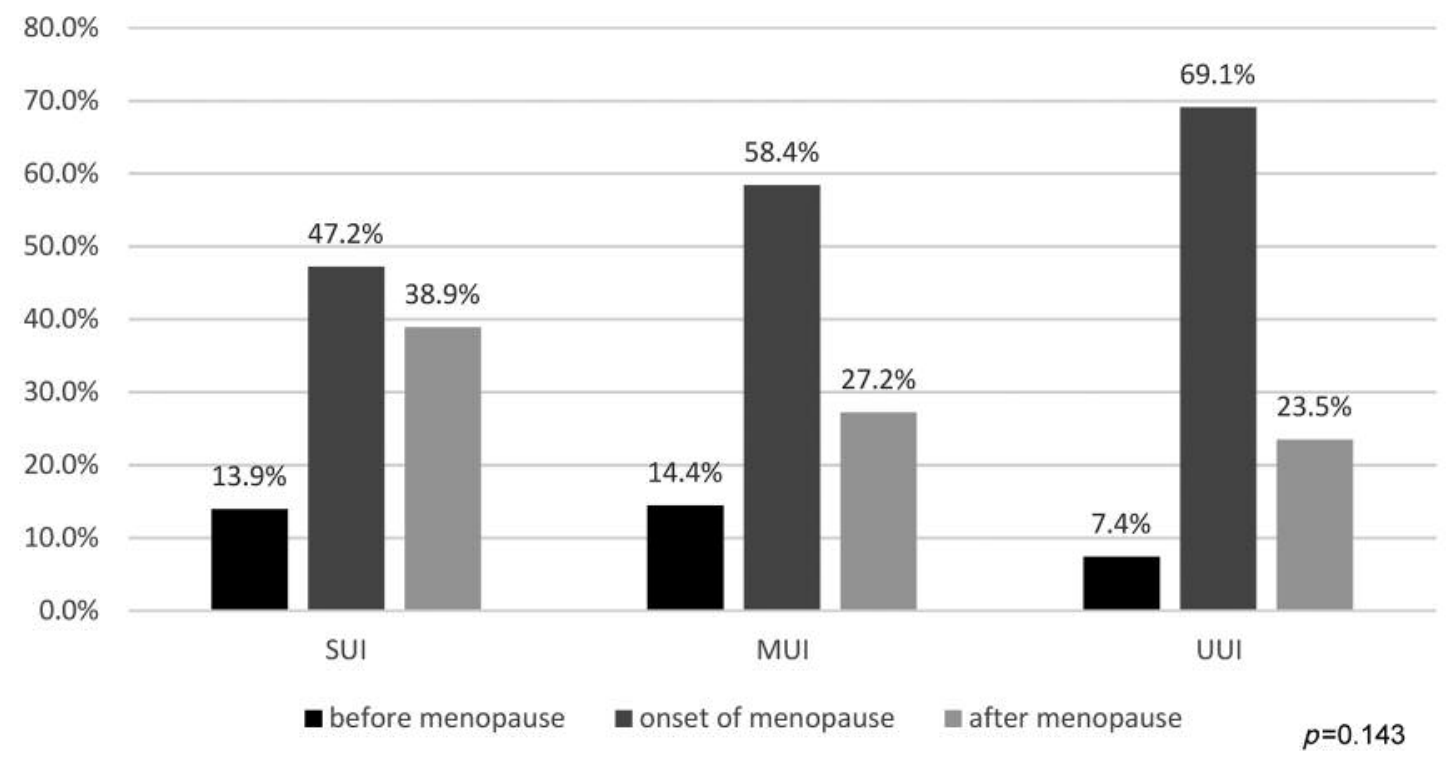

Figure 4. Onset of urinary incontinence in relation to postmenopausal status.

For spontaneous vaginal delivery, the 15-year cumulative incidence of pelvic floor disorders after first delivery have been described as $34.3 \%$ for SUI (11). Other authors described that vaginal delivery is associated with an almost two-fold increase in the risk of long-term SUI and increased risk of UUI (12). It has to be stressed out that all patients included in the current analysis presented with UI and no healthy control group was analyzed. In the past, previous hysterectomy has been associated with UI, but studies show varying results regarding the association between the type 
of hysterectomy and UI (2-5). Other authors did not find any significant difference after hysterectomy compared to controls in the prevalence or incidence proportions of UI after 10 years follow-up (13). In the current analysis prior hysterectomy and types of incontinence showed a significant correlation. The results are possibly influenced by the age of patients.

Menopause was reported to be another important risk factor for developing UI. Especially UUI is more common following menopause (14), whereas SUI is more prevalent in the pre-menopause phase (15). Consistent with those studies our results showed a higher proportion of patients with UUI in the postmenopausal group and a higher percentage of SUI patients in the premenopausal group. Herein, the decreased expression level of estrogen receptor is suggested to play a key role in premenopausal development of SUI (15). Due to the fact that UUI appears to increase simultaneously with the years of estrogen deficiency (14), estrogen treatment has been supposed to prevent or even decrease prevalence of incontinence in elderly women. However, studies showed that a systematic estrogen therapy can increase the incidence of UI and worsen pre-existing incontinence (16-18). Neither the type of hormones, nor the form of application or dose taken was of any importance regarding the risk of developing UI (19). In the current analysis we were not able to show a significant correlation between the type of UI and patients with or without hormone replacement therapy.

We also focused on the beginning of UI symptoms in relation to menopause, but could not show any significant differences between the groups of SUI, MUI and UUI. It seems that menopausal status itself has an impact on the type of incontinence, but not on the onset of UI symptoms. Interestingly, the onset of UI symptoms occurred significantly earlier in patients presenting with SUI compared to patients with MUI or UUI, indicating that agerelated changes seem to contribute to the development of different UI types, as a kind of 'pathophysiological continuum'. In that respect, we did not analyze the role of an intact pelvic holding apparatus, especially a weakness of the bladder-holding apparatus, that is the anterior vaginal wall and the apical vaginal end. There is a causal relation of pelvic organ prolapse urinary incontinence (20). Therefore, with increasing age the development of pelvic organ prolapse is more likely and may contribute to worsen mild UI symptoms (SUI) to more severe symptoms (UUI or MUI).

Strengths and limitation of the study. The retrospective character has to be considered as a limitation of the study. Nevertheless, the use of standardized validated questionnaires and the high number of patients in this hospital-based study has to be considered as a strength.

\section{Conclusion}

We were able to show that additional anamnestic information helps further characterize the different types of urinary incontinence and consequently lead to an optimization of therapy options. Therefore, young and premenopausal patients should be more precisely interviewed regarding urinary loss while physical exercising or coughing/sneezing, whereas elderly postmenopausal women should be asked for involuntary loss of urine (means without being physically active). It seems that age-related changes may contribute to different types of incontinence so that further clinical research is needed to evaluate factors that influence the onset of UI in order to focus on suitable treatment options.

\section{Ethical Approval}

All procedures performed in studies involving human participants were in accordance with the ethical standards of the institutional and/or national research committee and with the 1964 Helsinki declaration and its later amendments or comparable ethical standards.

\section{Conflicts of Interest}

The Authors declare that they have no conflicts of interest.

\section{Authors' Contributions}

FT: Manuscript writing, project development, and data collection. JHW: data collection and statistical analysis. DR: data collection and manuscript editing. CP: data collection and manuscript editing. JCR: data collection and manuscript editing. PM: project development, and data collection. SL: manuscript writing, project development and data collection.

\section{References}

1 Nitti VW: The prevalence of urinary incontinence. Rev Urol 3(Suppl 1): S2-S6, 2001. PMID: 16985992

2 Bohlin KS, Ankardal M, Lindkvist $\mathrm{H}$ and Milsom I: Factors influencing the incidence and remission of urinary incontinence after hysterectomy. Am J Obstet Gynecol 216(1): 53 e51-53 e59, 2017. PMID: 27593942. DOI: 10.1016/j.ajog.2016.08.034

3 Milsom I, Ekelund P, Molander U, Arvidsson L and Areskoug B: The Influence of age, parity, oral contraception, hysterectomy and menopause on the prevalence of urinary incontinence in women. J Urol 149(6): 1459-1462, 1993. PMID: 8501788. DOI:10.1016/s0022-5347(17)36415-7

4 Brown JS, Sawaya G, Thom DH and Grady D: Hysterectomy and urinary incontinence: a systematic review. Lancet 356(9229): 535-539, 2000. PMID: 10950229. DOI: 10.1016/ S0140-6736(00)02577-0

5 Jackson SL, Scholes D, Boyko EJ, Abraham L and Fihn SD: Predictors of urinary incontinence in a prospective cohort of postmenopausal women. Obstet Gynecol 108(4): 855-862, 2006. PMID: 17012446. DOI: 10.1097/01.AOG.0000236446.17153.21 
6 Gyhagen M, Bullarbo M, Nielsen $\mathrm{T}$ and Milsom I: The prevalence of urinary incontinence 20 - years after childbirth: a national cohort study in singleton primiparae after vaginal or caesarean delivery. BJOG An Int J Obstet Gynaecol 120(2): 144151, 2013. PMID: 22413831. DOI: 10.1111/j.1471-0528. 2012.03301.x

7 Lakeman MME, Van Der Vaart CH, Van Der Steeg JW and Roovers J-PWR: Predicting the development of stress urinary incontinence 3 years after hysterectomy. Int Urogynecol J 22(9): 1179-1184, 2011. PMID: 21484363. DOI: 10.1007/s00192-0111427-y.

8 Kok AL, Burger CW, van de Weijer PH, Voetberg GA, PetersMuller ER and Kenemans P: Micturition complaints in postmenopausal women treated with continuously combined hormone replacement therapy: a prospective study. Maturitas 31(2): 143-149, 1999. PMID: 10227008. DOI: 10.1016/s03785122(98)00093-0

9 El-Azab AS, Mohamed EM and Sabra HI: The prevalence and risk factors of urinary incontinence and its influence on the quality of life among Egyptian women. Neurourol Urodyn 26(6): 783-788, 2007. PMID: 17455273. DOI: $10.1002 /$ nau.20412

10 Avery K, Donovan J, Peters TJ, Shaw C, Gotoh M and Abrams P: ICIQ: a brief and robust measure for evaluating the symptoms and impact of urinary incontinence. Neurourol Urodyn 23(4): 322-330, 2004. PMID: 15227649. DOI: 10.1002/nau.20041

11 Blomquist JL, Muñoz A, Carroll M and Handa VL: Association of delivery mode with pelvic floor disorders after childbirth. JAMA 320(23): 2438-2447, 2018. PMID: 30561480. DOI: 10.1001/jama.2018.18315

12 Tähtinen RM, Cartwright R, Tsui JF, Aaltonen RL, Aoki Y, Cárdenas JL, El Dib R, Joronen KM, Al Juaid S, Kalantan S, Kochana M, Kopec M, Lopes LC, Mirza E, Oksjoki SM, Pesonen JS, Valpas A, Wang L, Zhang Y, Heels-Ansdell D, Guyatt GH and Tikkinen KAO: Long-term impact of mode of delivery on stress urinary incontinence and urgency urinary incontinence: A systematic review and meta-analysis. Eur Urol 70(1): 148-158, 2016. PMID: 26874810. DOI: 10.1016/j.eururo. 2016.01.037

13 Christiansen UJ, Hansen MJ and Lauszus FF: Hysterectomy is not associated with de-novo urinary incontinence: A ten-year cohort study. Eur J Obstet Gynecol Reprod Biol 215: 175-179, 2017. PMID: 28633096. DOI: 10.1016/j.ejogrb.2017.06.022
14 Calleja-Agius J and Brincat MP: The urogenital system and the menopause. Climacteric 18(sup1): 18-22, 2015. PMID: 26366796. DOI: $10.3109 / 13697137.2015 .1078206$

15 Adamiak-Godlewska A, Tarkowski R, Winkler I, Romanek-Piva K, Skorupska K, Jakimiuk AJ and Rechberger T: Stress urinary incontinent women, the influence of age and hormonal status on estrogen receptor alpha and beta gene expression and protein immunoexpression in paraurethral tissues. J Physiol Pharmacol 69(1): 53-59, 2018. PMID: 29769420. DOI: 10.26402/jpp. 2018.1.05

16 Hormone replacement therapy aggravates postmenopausal urinary incontinence. Prescrire Int 15(84): 137-138, 2006. PMID: 16989027.

17 Quinn SD and Domoney C: The effects of hormones on urinary incontinence in postmenopausal women. Climacteric 12(2): 106113, 2009. PMID: 19259853. DOI: 10.1080/13697130802630083

18 Grady D, Brown JS, Vittinghoff E, Applegate W, Varner E, Snyder T and HERS Research Group: Postmenopausal hormones and incontinence: the Heart and Estrogen/Progestin Replacement Study. Obstet Gynecol 97(1): 116-120, 2001. PMID: 11152919. DOI: 10.1016/s0029-7844(00)01115-7

19 Grodstein F, Lifford K, Resnick NM and Curhan GC: Postmenopausal hormone therapy and risk of developing urinary incontinence. Obstet Gynecol 103(2): 254-260, 2004. PMID: 14754692. DOI: 10.1097/01.AOG.0000107290.33034.6f

20 de Boer TA, Kluivers KB, Withagen MIJ, Milani AL and Vierhout ME: Predictive factors for overactive bladder symptoms after pelvic organ prolapse surgery. Int Urogynecol J 21(9): 1143-1149, 2010. PMID: 20419366. DOI: 10.1007/ s00192-010-1152-y 